\title{
CFD Analysis of the Aerodynamics of a Business-Jet Airfoil with Leading-Edge Ice Accretion
}

\author{
X. $\mathrm{Chi}^{*}$ \\ Department of Mechanical Engineering, Michigan State University, East Lansing, Michigan 48824-1226
}

B. Zhu ${ }^{* \star}$ and T. I-P. Shih"

Department of Aerospace Engineering, Iowa State University, Ames, Iowa 50011-2271

H.E. Addy ${ }^{+}$and Y.K. Choo ${ }^{+}$

NASA - Glenn Research Center, Cleveland, Ohio 44135

\begin{abstract}
For rime ice - where the ice buildup has only rough and jagged surfaces but no protruding horns - this study shows two-dimensional CFD analysis based on the one-equation Spalart-Almaras (S-A) turbulence model to predict accurately the lift, drag, and pressure coefficients up to near the stall angle For glaze ice - where the ice buildup has two or more protruding horns near the airfoil's leading edge - CFD predictions were much less satisfactory because of the large separated region produced by the horns even at zero angle of attack. This CFD study, based on the WIND and the Fluent codes, assesses the following turbulence models by comparing predictions with available experimental data: $S-A$, standard $k-\varepsilon$, shear-stress transport, $v^{2}-f$, and differential Reynolds stress.
\end{abstract}

\section{INTRODUCTION}

When an aircraft flies into environments, where meteorological conditions can cause ice to form on its wings, the aircraft's ability to maintain flight will diminish quickly with time unless there are ways to eliminate the ice formed. This is because with ice buildup, which occurs mostly on the wing/airfoil's leading edge, not only is the lift reduced, but also stall will occur at much lower angles of attack. ${ }^{1}$ If the maximum lift force that can be generated by the aircraft is less than its weight, then the aircraft will fall from the sky. Even if the lift is sufficient to sustain flight, uneven ice buildup on the wings can produce flight control problems. Thus, it is critically important to understand the different ice shapes that can form on the wings and how they affect aerodynamics.

The effects of accrued ice on aircraft aerodynamics can be studied by flight tests, wind-tunnel measurements, and computational fluid dynamics (CFD) simulations. Flight tests are the most realistic but are expensive. Tests in wind tunnels offer a controlled environment, but cannot

\footnotetext{
* Graduate Student.

** Research Fellow.

\# Professor and Chair. Associate Fellow AIAA.

+ Aerospace Engineer, Icing Branch. Member AIAA.
}

This material is declared a work of the U.S. Government and is not subject to copyright protection in the United States. reproduce actual flight conditions since not all dimensionless parameters can be matched. CFD is the most cost effective method and has the ability to simulate actual geometric and flight conditions. However, its accuracy depends on the quality of the grid and the ability of the turbulence model to reproduce the key flow physics.

\section{Previous Work}

When studying aerodynamics of wings with ice accretion by using CFD, the generation of high-quality structured grids is a major challenge. This is true even for two-dimensional (2-D) analyses involving 2-D ice shapes on 2-D airfoils. Chi, et al. ${ }^{2}$ presented methods to generate high-quality single- and multi-block structured grids for complicated 2-D ice shapes. They demonstrated their methods on a naturally laminar flow airfoil (NLF0414 ${ }^{1}$ ) with a glaze ice (623 ice shape ${ }^{1}$ ), which had two protruding horns. To generate high-quality multi-block grids, they showed that a "thick wrap-around" grid is needed to ensure that grid points clustered next to solid surfaces do not propagate into the interior of the flow domain (Fig. 1). To minimize and confine the adverse effects of the ice's jagged surface on the quality of the grid, they suggested using a transitional layer next to solid surfaces (Fig. 2). They also developed a method for generating single-block grids for iced airfoil based on an idea presented by Tai. $^{3}$

Since multi-block grids can converge slower, Zhu, et al. ${ }^{4}$ studied the effects of blocking strategies on the convergence rate to steady-state solutions. They showed that when a single-block grid is partitioned into a multi-

This is a preprint or reprint of a paper intended for presentation at a conference. Because changes may be made before formal publication, this is made available with the understanding that it will not be cited or reproduced without the permission of the author. 
block grid with block boundaries perpendicular to the flow direction, the number of iterations needed to converge is about the same as that for the single block grid. When that same single-block grid is partitioned into a multi-block grid with block boundaries parallel to the flow direction (e.g., wrap-around grids), convergence rate can deteriorate if those block boundaries are too close to the airfoil/ice surface. If those boundaries are sufficiently far away, then the convergence rate can be nearly as good as single-block grids.

Zhu, et al..$^{5}$ examined the grid-generation and the blocking techniques of $\mathrm{Chi}$, et al. ${ }^{2}$ and $\mathrm{Zhu}$, et al. ${ }^{4}$ by applying them to a much more complicated ice shape, the $145 \mathrm{~m}$ ice shape ${ }^{1}$, which has multiple and highly extended horns in close proximity to each other. Even for this highly challenging ice shape, they found that high-quality single- and multi-block grids can be generated but local elliptic smoothing is needed (Fig. 3). They also found that variable thickness wrap-around grids are needed for multi-block grids. On convergence rate, they found that one needs to monitor not just the residual for the flow variables, but also the residual for the turbulence quantities. Though the lift and the drag coefficients converge when the flow variables converge, the flow patterns were found not to converge until the turbulence quantities converged. The residual for the turbulence quantities were found to converge slower than the residual for the flow variables.

To date, most CFD studies on 2-D iced airfoils have focused on the following: grid generation methods, grid resolution, turbulence models, and lift and drag coefficients as a function of the angle of attack (see, e.g., Refs. 2, 4, 5, and 6 to 11 ). Though much has been learned from these studies, accuracy of CFD predictions is still unclear. For example, what are the error bounds and confidence level in the computed lift and drag coefficients as a function of angle of attack? In addition, relatively little emphasis has been made on understanding the flow field induced by the ice accrued on the airfoil and how well they are predicted. One reason is that very little experimental data are available that can be used to assess the accuracy of such CFD predictions. Recently, experimental data for the $\mathrm{x}$-component velocity have been made available for a business-jet airfoil (GLC305 ${ }^{1}$ ) with a 944 glaze ice shape ${ }^{1}$ and is reported in Ref. 12. The availability of this experimental data enables a more thorough interrogation of the CFD results generated. That is, in addition to lift, drag, and pressure coefficients, the detailed flow field can also be interrogated with confidence to provide better understanding of how ice shapes affect aerodynamics.

\section{Objective and Approach}

With the above backdrop, the main objective of this study is to understand how well CFD can predict lift, drag, surface pressure, and the velocity field as a function of the angle of attack for 2-D iced airfoils. The accuracy of CFD predictions will be assessed by comparing computed results with experimentally measured lift, drag, surface pressure, and velocity field.

Since it is now possible to generate high-quality grids for geometrically complicated 2-D iced airfoils through the work described in Refs. 2, 4, and 5, this study on accurate CFD predictions focuses on the effects of turbulence models, the other major source of error. Of particular interest is how well state-of-the-art models can predict the aerodynamics induced by glaze and rime ice shapes. Glaze and rime ice shapes, formed under different icing conditions, constitute the two fundamental ice shapes. Though both ice surfaces are rough and jagged, glaze ice also has horns but rime ice does not. Thus, these two ice shapes produce very different flow fields, which may have different requirements on turbulence modeling. For rime ice, which produces only very small separated regions at all angles of attack except near stall, a simpler turbulence model may be adequate. For glaze ice, which can produce large separated regions downstream of the horns even at zero angle of attack, one- or two-equations models may be inadequate. Differential Reynolds stress models that can account for each of the Reynolds stresses individually may be needed to predict the effects of streamline curvature and the time-lagged response of turbulence to changes in the mean flow.

In order to examine as many turbulence models as possible, two codes were used in this study. One is the widely used, open-source code, referred to as WIND, which was used in the work reported in Refs. 2, 4, 5, 7, 8, 10 , and 11. The other is Fluent, a popular commercial CFD code with many turbulence models. References on WIND and Fluent are provided in Section 3, when these codes are described in more detail.

The organization of the remainder of this paper is as follows. Section 2 summarizes the glaze and rime, icedairfoil problems studied. Section 3 outlines the formulation and the numerical method of solution used in the codes and the turbulence models examined. Section 4 presents the results generated.

\section{PROBLEM DESCRIPTION}

The airfoil, the ice shapes, and the flow conditions selected for study are those for which the flow field is sufficiently complicated and for which there are experimental data that can be used to assess the accuracy of the CFD predictions. The airfoil selected is the business-jet airfoil (GLC305 ${ }^{1}$ ). The glaze ice selected is the 944 ice shape with two large protruding horns. The rime ice selected is the 212 ice shape, which has considerable surface jaggedness but no protruding horns. The airfoil and the ice shapes about the airfoil's leading edge are shown in Figs. 4 and 5. See Ref. 1 for details of the geometry. 
In this study, the freestream Mach number (M) is 0.12 . Two freestream static pressures $(P=20.5$ psi and $37.0 \mathrm{psi}$ ) and two Reynolds numbers based on the free stream conditions and the chord length $\left(\mathrm{Re}=3.5 \times 10^{6}\right.$ and $6.0 \times 10^{6}$ ) were investigated. The angles of attack (AOA) simulated are $0,4,6,7,8,9$ or the 944 ice and 0 , $4,6,7,8,9,10,11,12$ for the 212 ice. The reason for simulating so many angles of attack is to get the details on lift and drag coefficients about the stall angle.

\section{FORMULATION AND NUMERICAL METHOD OF SOLUTION}

Two different CFD codes were used to generate solutions for the iced-airfoil problems described in the previous section. One is a widely used, open-source code, known as WIND. ${ }^{13-14}$ The other is a popular commercial code, Fluent. ${ }^{15}$ These codes were selected because they are highly versatile and contain a wide range of turbulence models.

For both codes, the flow past the GLC305 airfoil with the 944 and 212 ice is modeled by the ensemble-averaged conservation equations of mass (continuity), momentum (full compressible Navier-Stokes), and energy for a thermally and calorically perfect gas. For most simulations, the one-equation Spalart-Allmaras (S-A) model $^{16}$ is used to mimic the effects of turbulence. For iced airfoils, Chuang \& Addy ${ }^{10}$ showed the S-A model to out-perform two-equation turbulence models including the highly regarded shear-stress transport (SST) model. ${ }^{17,18}$ For Fluent, the following turbulence models were investigated: $\mathrm{S}-\mathrm{A},{ }^{16}$ SST, ${ }^{17,18}$ standard $\mathrm{k}-\varepsilon,{ }^{19}$ Durbin's $v^{2}-f$ model, ${ }^{20}$ and a differential Reynolds stress model. $^{21,22}$ With Fluent, the near-wall region is always modeled by the two-layer model of Chen and Patel. ${ }^{23}$ In all simulations with both WIND and Fluent, the conservation equations and the turbulence models are integrated to the wall, where the no-slip and adiabatic wall conditions were imposed (i.e., wall functions were not used).

The numerical methods of solution used are as follows. For WIND, the convective terms were approximated by second-order Roe upwind differencing. Since only steady-state solutions are of interest, time marching to steady state was accomplished by an implicit method based on ADI-type approximate factorization with local time stepping. For Fluent, which uses a finitevolume method, fluxes at the cell faces are interpolated by using second-order upwind differencing. The SIMPLE algorithm was used to generate steady-state solutions. For this segregated solver, the convergence criteria used are to ensure that normalized residual is less than $10^{-6}$ for the energy equation and less than $10^{-3}$ for all other equations.

To ensure proper comparison between the codes and among the turbulence models, both WIND and Fluent used essentially the same grid systems as explained below. For WIND, all grid systems generated consist of two overlapping single-block grids. One is a fine grid next to the airfoil, extending 0.6 chord length from the airfoil in all directions (referred to as the inner grid). The other is a coarser grid $(125 \times 21)$ that overlaps the fine grid by 0.1 chord length and extends 15 chord lengths away from the airfoil in all directions (referred to as outer grid). The inner grid is the single-block grid of interest. While generating this grid, grid lines were clustered next to the airfoil surface so that the first grid point is within a $y+$ of unity. Along the airfoil surface, equal arc-length was employed to create a grid as smooth as possible.

Since Fluent does not accept overlapping grids, the grids used by WIND and Fluent are not exactly the same. The inner grid used by WIND is also used in Fluent. The outer grid used, however, does differ from the one used by WIND. In Fluent, the outer grid is an unstructured grid in which the square root of the cell area is comparable to the grid spacing of the outer grid used in WIND. Since the grids closest to the iced airfoils are identical up to 0.6 chord length for both codes and that is where all of the interesting flow features take place, there is a basis to compare the two codes.

In this study, five different inner grids were used. For all five inner grids, the same outer grid is used - structured for WIND and unstructured for Fluent. The details of the inner grids are as follows: For the business-jet airfoil without ice (referred to as clean), the inner grid has $913 \mathrm{x}$ 101 grid points (Fig. 6). The second grid (referred to as S25) has the 944 ice shape represented by only $25 \%$ of the control points (not shown but similar to the one shown in Fig. 7 top). This means that there is smoothing of the jagged ice geometry, which makes grid generation easier. For this grid system, the inner grid has 941 x 101 grid points. The third grid (referred to as SV1) uses $100 \%$ of the control points (Fig. 7 top). For this grid, the 944 ice shape was smoothed less so that grid generation is more tedious in having to capture more details of the jagged geometry. For this grid system, the inner grid also has 941 x 101 grid points. The fourth grid (referred to as SV2) also uses $100 \%$ of the control points. SV2 differs from SV1 in having more grid points in the region next to solid surfaces ( $989 \times 129$ grid points). The fifth grid generated is for the 212 ice, and it has $987 \times 131$ grid points (Fig. 7 bottom).

All grid systems described above were generated by using transfinite interpolation ${ }^{24,25}$ in the manner described in Refs. 2, 4, and 5 with varying degrees of local elliptic smoothing. Also, all of these grid systems are arrived at after an extensive grid-independent study.

\section{RESULTS}

The main objective of this study is to assess how well CFD can predict lift, drag, surface pressure, and the velocity field as a function of the angle of attack for a 2-D 
airfoil with a glaze or a rime ice shape built upon its leading edge. The focus is on the effects of turbulence modeling on the predictions.

\section{Clean Airfoil}

Figures 8 and 9 show the results obtained by using the WIND code with the S-A turbulence model for the clean GLC305 airfoil. These figures show that CFD can predict the lift and surface pressure coefficients quite well for angle of attack up to near stall. But, the stall angle is slightly under predicted. One reason for not predicting the lift coefficient correctly near stall is that the flow under those conditions becomes unsteady. In this study, only steady-state solutions were sought.

\section{Airfoil with Glaze Ice}

Figures 10 to 12 show the results obtained by using the WIND code with the S-A turbulence model for the GLC305 airfoil with the 944 glaze ice. These figures show CFD to under predict the lift and drag coefficients at all angles of attack. The predicted pressure coefficient is shifted towards the leading edge, indicating incorrect predictions of the separated region induced by the horns.

To ensure that grid resolution or ice-shape smoothing were not the cause of the inaccuracies, simulations were performed with grids based on smoothed (S25) and unsmoothed (SV1) ice shapes as well as increased grid resolution (SV2). Figure 13 shows these effects to be insignificant. Note that SV1 is already a very fine mesh, and is the one used in all remaining simulations of the 944 ice with the WIND and Fluent codes. Thus, using a smoothed ice shape (e.g., one represented by only $25 \%$ of the control points) may be adequate when predicting lift and drag. This can be significant, since grid generation is easier and less time consuming with a smoother ice surface.

In an attempt to improve predictions, more sophisticated turbulence models were evaluated by using the Fluent code, which has more turbulence models encoded. Figures 14 and 15 show that WIND and Fluent gave nearly the same results when the S-A model is used on the same inner grid. This gives some confidence towards using two different codes to evaluate a variety of turbulence models. Figures 14 and 15 show that S-A gives the best results for the lift and drag coefficients, confirming the findings of Chung \& Addy. ${ }^{10}$ SST and the standard $k-\varepsilon$ models were found to under predict lift and to over predict drag when compared to the other models. Differential Reynolds stress and $v^{2}-f$ models gave the best results for the drag coefficient at $\mathrm{AOA}=4^{\circ}$ but not at $\mathrm{AOA}=6^{\circ}$. Also, the lift is severely under predicted at $\mathrm{AOA}=6^{\circ}$. The less than satisfactory results for the $v^{2}-f$ and the differential Reynolds stress models is that Fluent uses the one-equation Chen and Patel two-layer model in the near wall region.

\section{Airfoil with Rime Ice}

Figures 16 and 17 show the results obtained by using the WIND code with the S-A turbulence model for the GLC305 airfoil with the 212 rime ice. These figures show CFD to predict accurately the lift, drag, and pressure coefficients until near stall. This shows CFD predictions of airfoils with rime ice, where separated regions are small, to be quite reliable. Similar to the situation with the clean airfoil, the stall angle is slightly under predicted. Again, the reason is that the flow becomes unsteady near stall, and only steady-state solutions were generated in this study.

\section{Prediction of the Velocity Field}

Figures 18 to 20 show the predicted contours of the $x$ component velocity magnitude for the GLC305 airfoil with 944 glaze ice at $\mathrm{AOA}$ equal to $0^{\circ}, 4^{\circ}$, and $6^{\circ}$. Also, shown are the experimentally measured values reported in Ref. 12. Comparing the CFD results with the measured ones shows that CFD incorrectly predicts the size of the separated region downstream of the horn on airfoil's suction side. This caused the surface pressure to be shifted, which in turn caused lift and drag to be under predicted.

Figures 21 and 22 show the CFD and measured contours of the $\mathrm{x}$-component velocity magnitude for the GLC305 airfoil with 212 rime ice at AOA equal to $6^{\circ}$ and $8^{\circ}$. These figures show the separated region to be predicted correctly though there are still discrepancies between the CFD and the measured results. Since the lift, drag, and pressure coefficients were predicted well by $\mathrm{CFD}$, this indicates that predicting the separated region correctly is paramount.

\section{SUMMARY}

This study showed that if there are no large separated regions (e.g., the 212 ice), then CFD based on the oneequation Spalart-Allmaras turbulence model can predict accurately the lift, drag, and pressure coefficients. Thus, CFD can predict airfoils with rime ice quite adequately for angles of attack up to near stall. For airfoils with glaze ice (e.g., 944 ice), where the horns produce large separated regions about the airfoil's leading edge, CFD predictions are much less satisfactory even at low angles of attack. For airfoils with glaze ice, this study showed that even the $v^{2}-f$ and the differential Reynolds stress models do not provide better results than the simple S-A model, which was found to provide the best results. However, more study is needed for the $v^{2}-f$ and the differential Reynolds stress models in which the near-wall treatment is not the two-layer model of Chen and Patel. Comparing the predicted $\mathrm{x}$-component velocity magnitude with the measured ones show CFD to over predict the size of the separated region induced by the horns, and hence incorrectly predicting lift, drag, and pressure coefficients. 
This study also showed that for glaze ice, some smoothing of the ice shape is acceptable, which makes grid generation easier.

Finally, it is noted that WND and Fluent provided nearly identical results for lift, drag, and pressure coefficients when the following were the same: grid, turbulence model (S-A), and similar order of accuracy for the solution algorithms.

\section{ACKNOWLEDGEMENT}

This work was supported by NASA grant NAG 32576 from NASA - Glenn Research Center. The authors are grateful for this support. The authors are also grateful to Fluent for providing the Fluent-UNS code.

\section{REFERENCES}

1. Addy, H.E., "Ice Accretions and Icing Effects for Modern Airfoils," NASA/TP-2000-210031, April 2000.

2. Chi, X., Zhu, B., Shih, T.I-P., Slater, J.W., Addy, H.E., and Choo, Y.K., "Computing Aerodynamic Performance of 2D Iced Airfoils: Blocking Topology and Grid Generation," AIAA Paper 2002-0381, January 2002.

3. Tai, T.C., "Single-Block Structured BodyConforming Grid for Complex Geometries," Numerical Grid Generation in Computational Field Simulations, edited by B.K. Soni, J.F. Thompson, J. Hauser, and P. R. Eiseman, ISGG, 2000, pp. 91-100.

4. Zhu, B., Chi, X., Shih, T.I-P., and Slater, J.W., "Computing Aerodynamic Performance of 2D Iced Airfoils: Blocking Strategies and Convergence Rate," AIAA Paper 2002-3049, June 2002.

5. Zhu, B., Chi, X., Shih, T.I-P., Slater, J.W., Addy, H.E., and Choo, Y., "Computing Aerodynamic Performance of 2-D Iced Airfoils with Structured Grids," AIAA Paper 2003-1071, January 2003.

6. Choo, Y., Slater, J., Henderson, T., Bidwell, C., Braun, D., and Chung J., "User Manual for Beta Version of Turbo-GRD: A Software System for Interactive Two-Dimensional Boundary/Field Grid Generation, Modification, and Refinement," NASA TM-1998-206631, 1998.

7. Chung, J., Reehorst, A.L., Choo, Y.K., and Potapczuk, "Effects of Airfoil Ice Shape Smoothing on the aerodynamic Performance," AIAA Paper 983242, July 1998.

8. Chung, J., Choo, Y., Reehorst, A., Potapczuk, and Slater, J., "Navier-Stokes Analysis of the Flowfield Characteristics of an Ice Contaminated Aircraft Wing," AIAA 99-0375.

9. Vickerman, M., Choo, Y., Braun, D., Baez, M., and Gnepp, S., "SmaggIce: Surface Modeling and Grid
Generation for Iced Airfoils, Phase 1 Results," AIAA Paper 2000-0235, Jan. 2000.

10. Chung, J.J. and Addy, H.E., "A Numerical Evaluation of Icing Effects on a Natural Laminar Flow Airfoil," AIAA Paper 2000-0096, Jan. 2000.

11. Shim, J., Chung, J., and Lee, K.D., "A Computational Investigation of Ice Geometry Effects on Airfoil Performances," AIAA Paper 2001-0540, Jan. 2001.

12. Broeren, A.P., Addy, H.E., and Bragg, M.B., "Flowfield Measurements about an Airfoil with Leading-Edge Ice Shapes," AIAA Paper 2004-0559, Jan. 2004.

13. Power, G.D. and Underwood, M.L., "WIND 2.0: Progress on an Applications-Oriented CFD Code," AIAA Paper 99-3212, June 1999.

14. Michal, T. and Oser, M., "Improving Zonal Coupling Accuracy and Robustness in the WIND Code," AIAA Paper 2001-0222, January 2001.

15. http://www.fluent.com/software/fluent/index.htm.

16. Spalart, P.R. and Allmaras, S.R., "A One-Equation Turbulence Model for Aerodynamic Flows," AIAA Paper 1992-439, January 1992.

17. Menter, F.R., 1991, "Performance of Popular Turbulence Models for Attached and Separated Adverse Pressure Gradient Flows," AIAA J., Vol. 30, No. 8, pp. 20662071.

18. Menter, F.R., 1993, "Zonal Two-Equation k- $\omega$ Turbulence Models for Aerodynamic Flows," AIAA Paper 93-2906.

19. Launder, B.E. and Spalding, D.B., "The Numerical Computation of Turbulent Flows," Computer Methods in Applied Mechanics and Engineering, Vol. 3, 1974, pp. 269-289.

20. Durbin, P.A., "A Reynolds Stress Model for NearWall Turbulence," Journal of Fluid Mechanics, pp. 465-498, Vol. 249, 1993

21. Fu, S., Launder, B.E., and Leschziner, M.A., "Modeling Strongly Swirling Recirculating Jet Flow with Reynolds-Stress Transport Closures," Sixth Symposium on Turbulent Shear Flows, Toulouse, France, 1987

22. Gibson, M. M. and Launder, B. E., "Ground Effects on Pressure Fluctuations in the Atmospheric Boundary Layer," J. of Fluid Mechanics, Vol. 86, 1978, pp. 491511.

23. Chen, H.C. and Patel, V.C., "Near-Wall Turbulence Models for Complex Flows Including Separation," AIAA J., Vol. 26, No. 6, 1988, pp. 641-648.

24. Shih, T.I-P., Bailey, R.T., Nguyen, H.L., and Roelke, R.J., "Algebraic Grid Generation for Complex Geometries," International J. for Numerical Methods in Fluids, Vol. 13, 1991, pp. 1-31.

25. Steinthorsson, E., Shih, T.I-P., and Roelke, R.J., "Enhancing Control of Grid Distribution in Algebraic Grid Generation," International J. for Numerical Methods in Fluids, Vol. 15, 1992, pp. 297-311. 

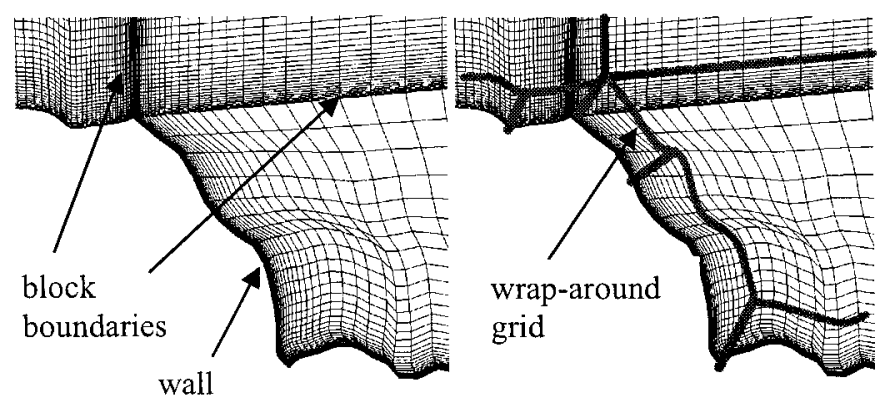

(a)

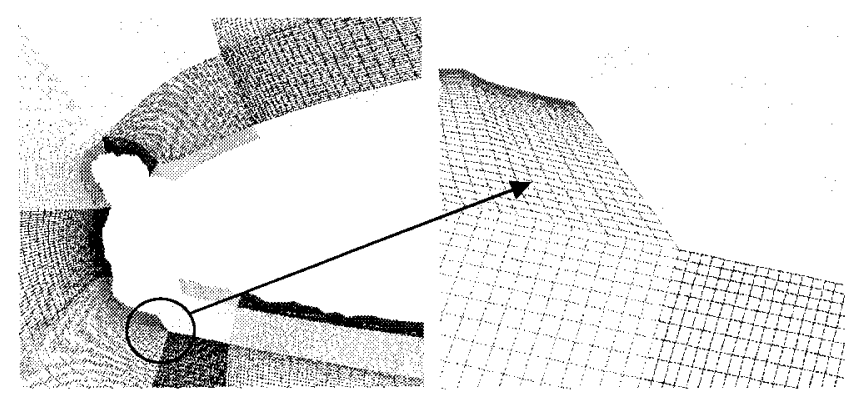

(b)

Fig. 1. NLF0414 airfoil with 623 ice. (a) Grid lines clustered next to solid boundaries propagate into domain along block boundaries. (b) Grid with wrap-around grid.

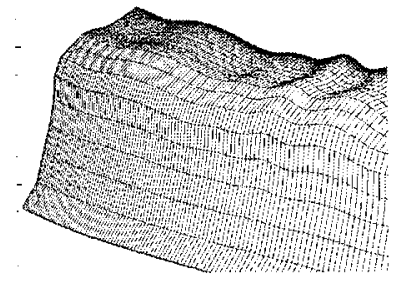

(a)

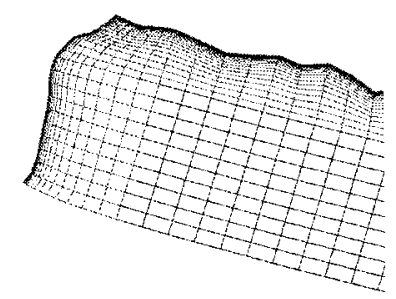

(b)
Fig. 2. (a) No transition layer. (b) With transition layer.

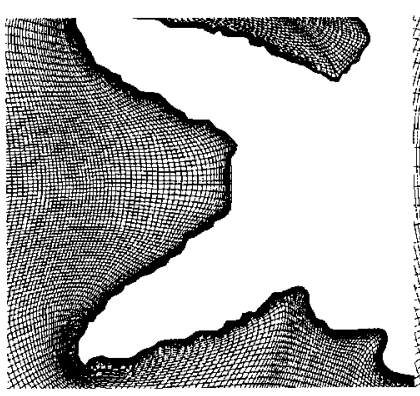

(a)

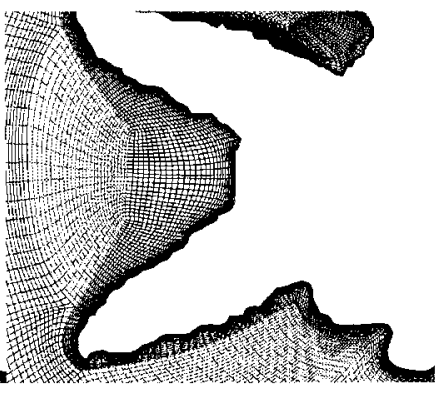

(b)
Fig. 3. Commercial-transport airfoil with $145 \mathrm{~m}$ ice. (a) Single-block grid. (b) Multi-block grid.

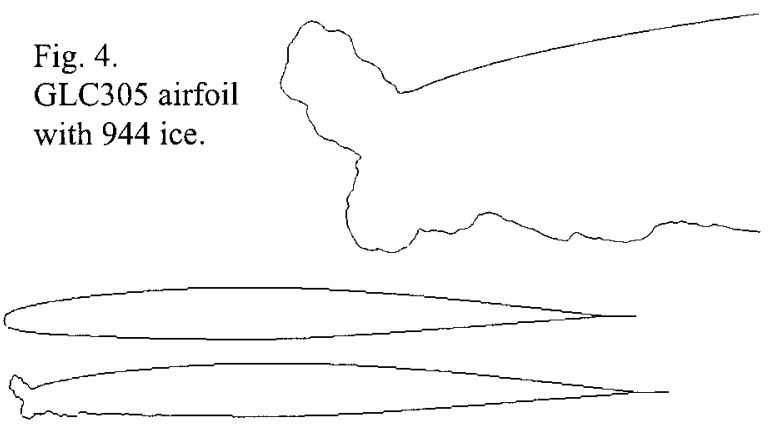

Fig. 5.

GLC305 airfoil with 212 ice.
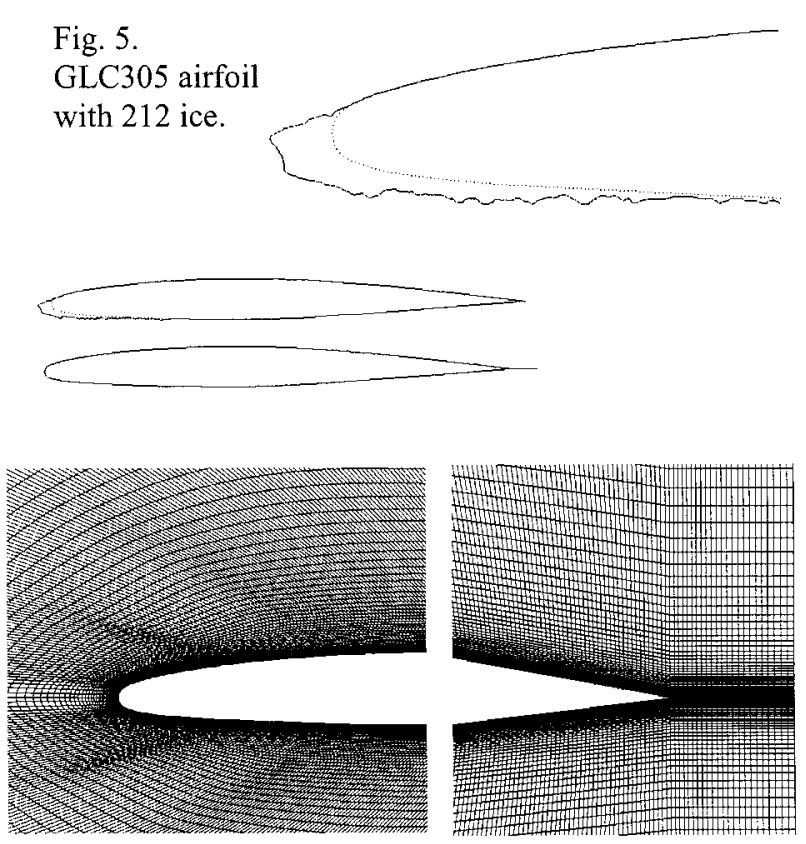

Fig. 6. Grid used for GLC305 airfoil without ice (clean)

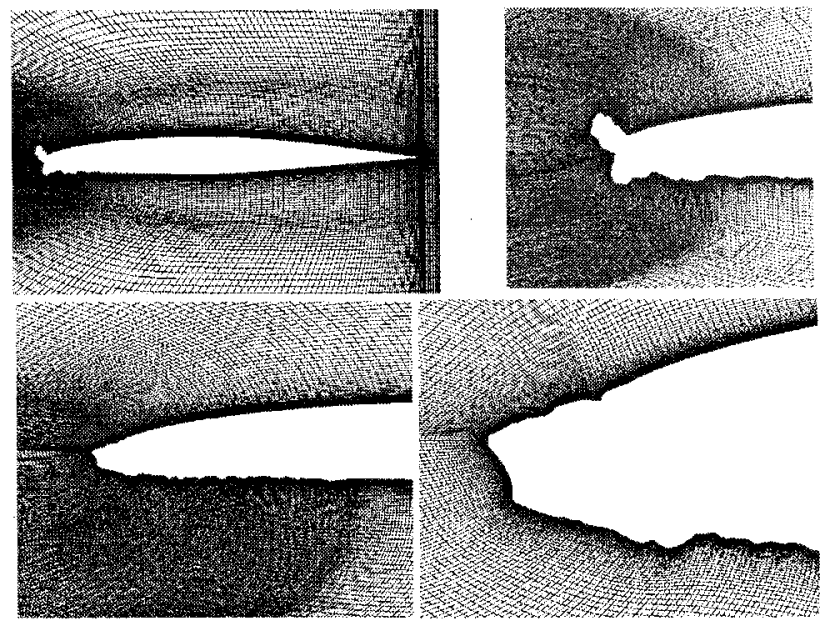

Fig. 7. Grid about GLC305 airfoil with 944 ice (top) and 212 ice (bottom). 


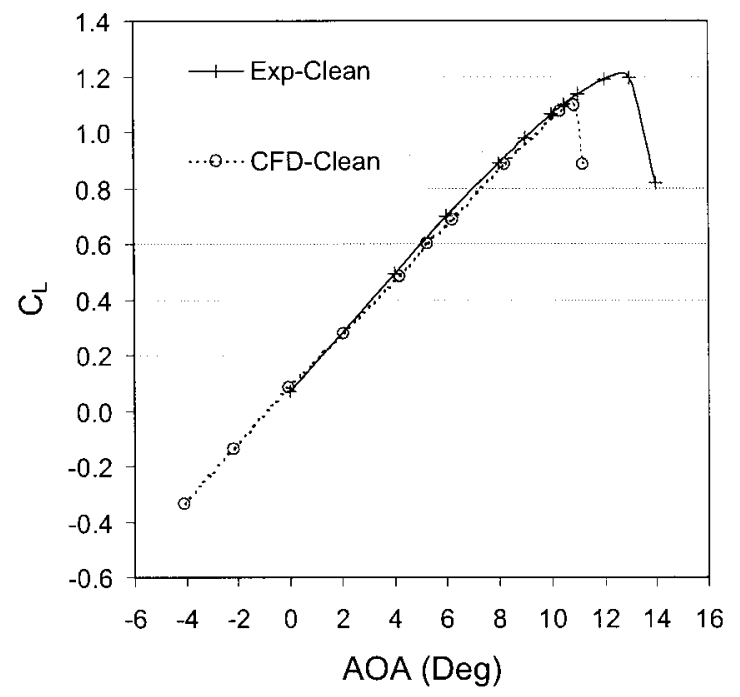

Fig. 8. Computed and measured lift coefficient for clean GLC305 airfoil $\left(M=0.12, P=20.5 \mathrm{psi}, \mathrm{Re}=3.5 \times 10^{6}\right)$. CFD: WIND, S-A model.
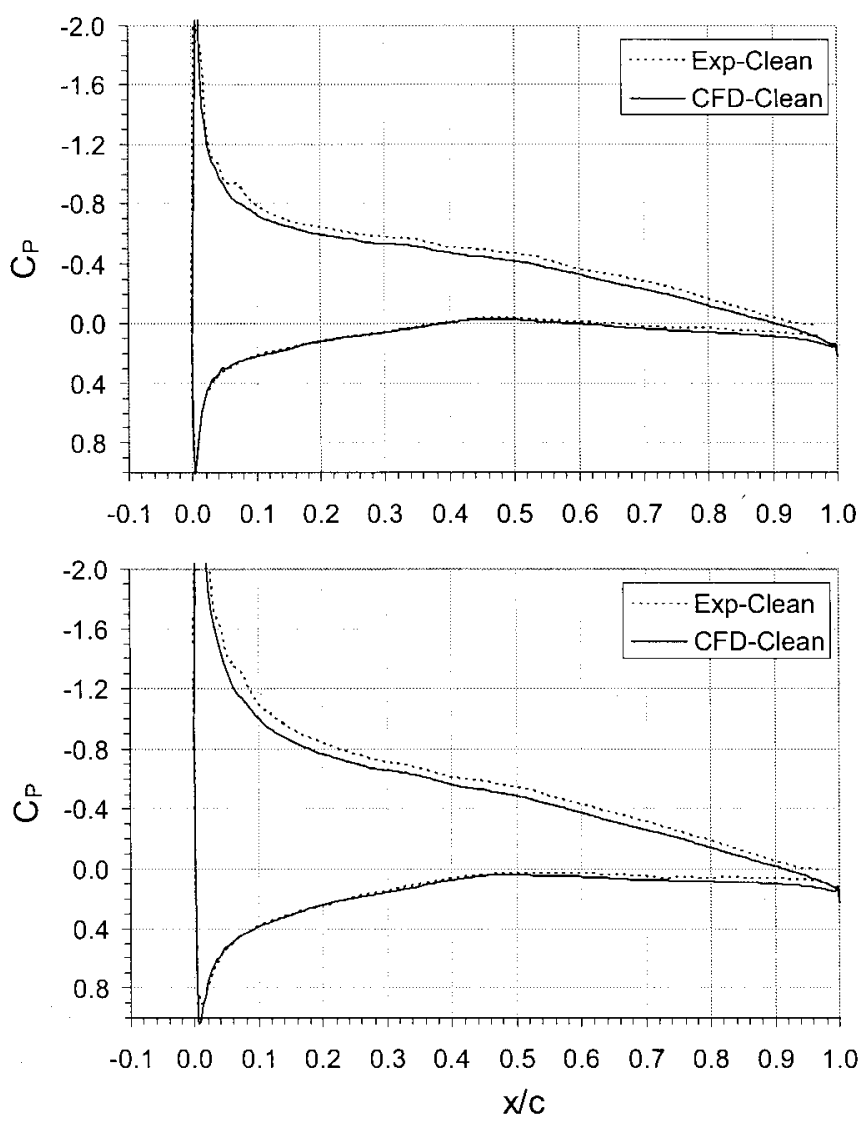

Fig. 9. Computed and measured pressure coefficient for clean GLC305 airfoil $\left(\mathrm{M}=0.12, \mathrm{P}=20.5 \mathrm{psi}, \mathrm{Re}=3.5 \times 10^{6}\right)$. Top: $\mathrm{AOA}=4^{\circ}$. Bottom: $\mathrm{AOA}=6^{\circ}$. CFD: Wind, S-A model.

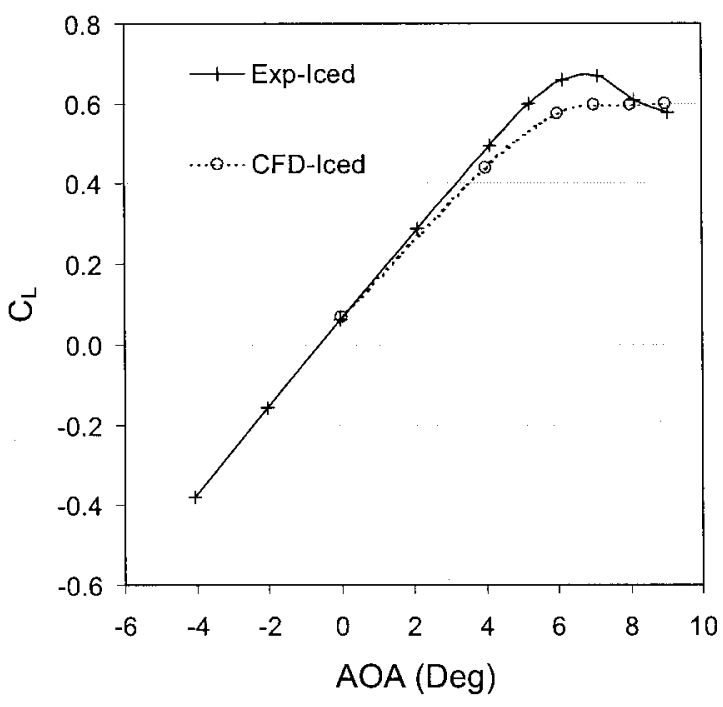

Fig. 10. Computed and measured lift coefficient for GLC305 airfoil with 944 ice $(\mathrm{M}=0.12, \mathrm{P}=20.5 \mathrm{psi}, \mathrm{Re}=$ $3.5 \times 10^{6}$ ). CFD: WIND, S-A model.
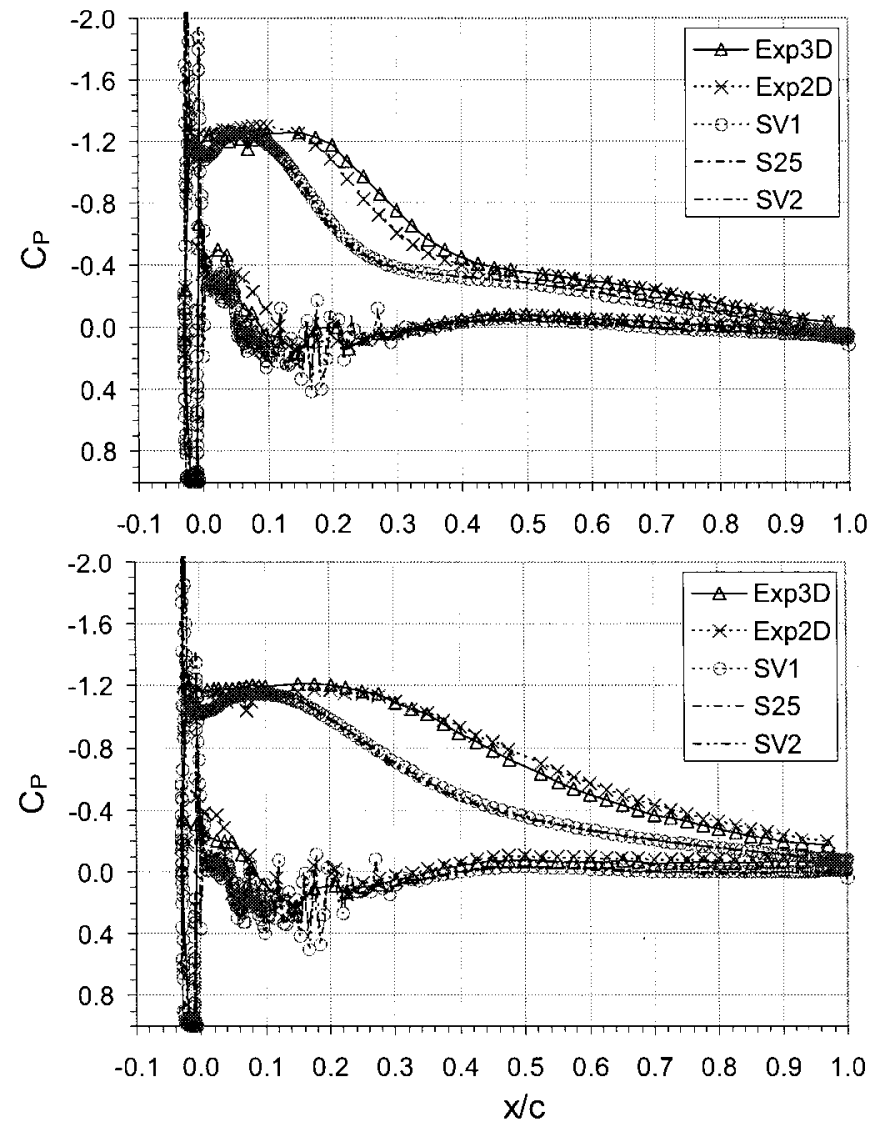

Fig. 11. Computed and measured pressure coefficient for GLC305 airfoil with 944 ice $\left(M=0.12, P=20.5\right.$ psi, $\left.R e=3.5 \times 10^{6}\right)$. Top: $\mathrm{AOA}=4^{\circ}$. Bottom: $\mathrm{AOA}=6^{\circ}$. CFD: Wind, S-A model. 


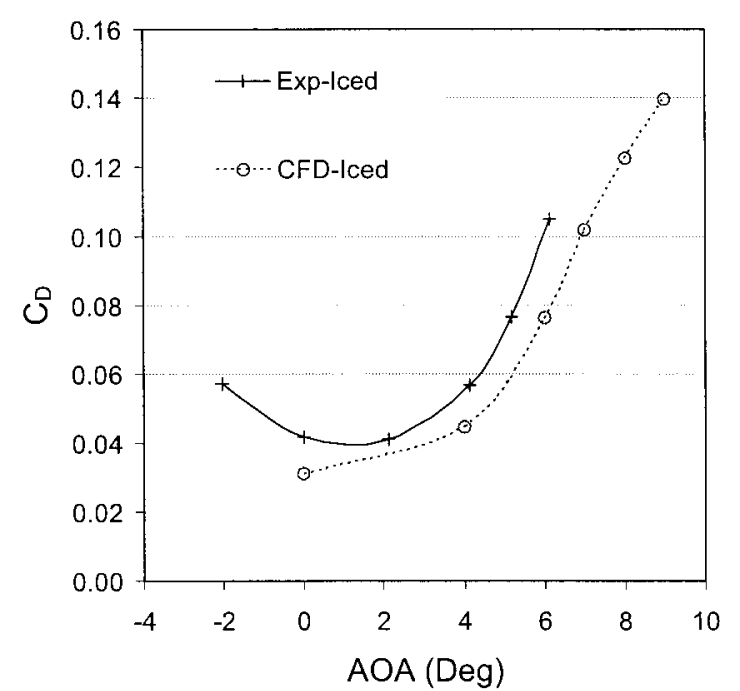

Fig. 12. Computed and measured drag coefficient for GLC airfoil with 944 ice $(\mathrm{M}=0.12, \mathrm{P}=20.5 \mathrm{psi}, \mathrm{Re}=3.5$ $x 10^{6}$ ). CFD: WIND, S-A model.

$\square$ S25 $\mathrm{SV} 1$ 圆 SV2
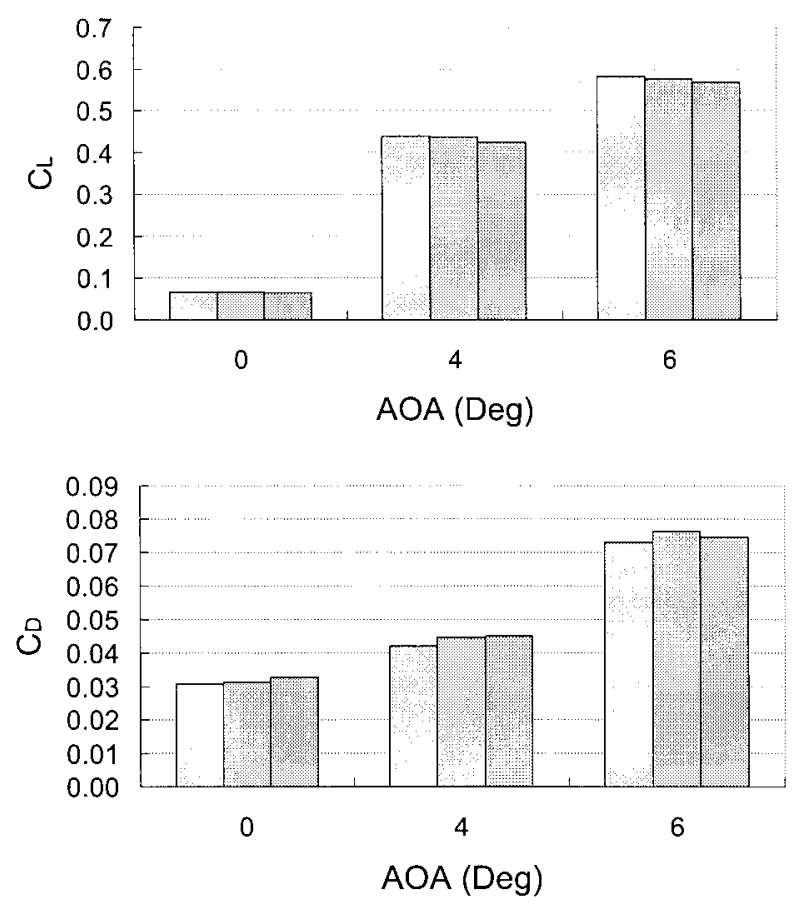

Fig. 13. Effects of grid resolution and smoothing 944 ice shape and grid $\left(\mathrm{M}=0.12, \mathrm{P}=20.5 \mathrm{psi}, \mathrm{Re}=3.5 \times 10^{6}\right)$. CFD: WIND, S-A model.

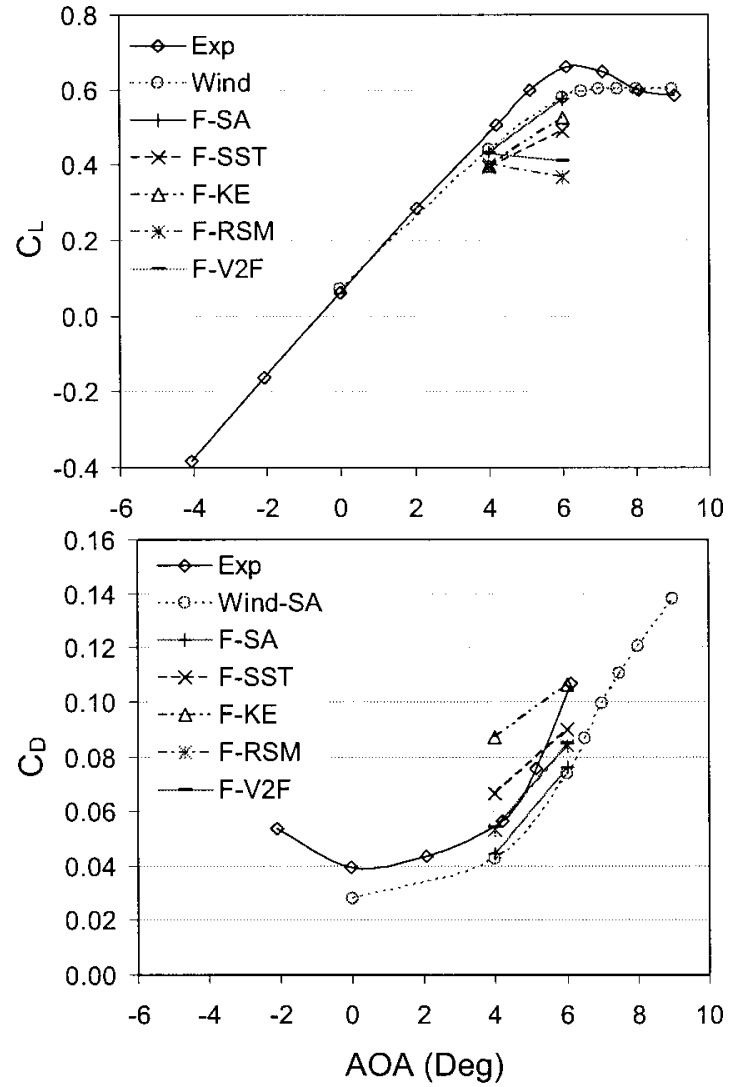

Fig. 14. Computed and measured lift coefficient for GLC305 airfoil with 944 ice $\left(M=0.12, P=37.0 \mathrm{psi}, \mathrm{Re}=6.0 \times 10^{6}\right)$.

CFD: WIND (S-A) and Fluent.
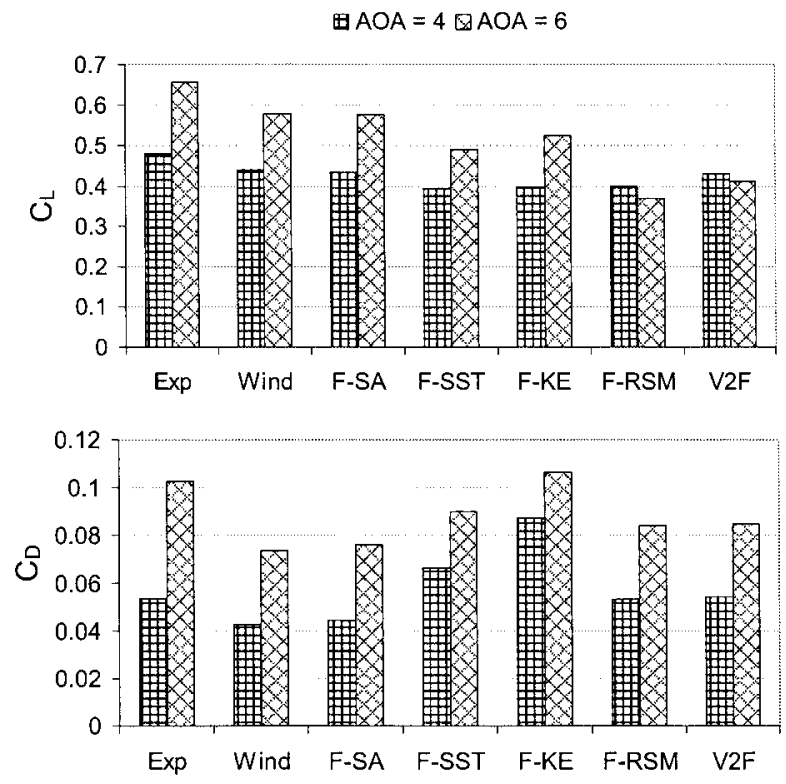

Fig. 15. Computed and measured lift and drag coefficient for GLC305 airfoil with 944 ice at $\mathrm{AOA}=4^{\circ}$ and $6^{\circ}(\mathrm{M}=0.12, \mathrm{P}$ $=37.0$ psi, $\operatorname{Re}=6.0 \times 10^{6}$ ). 

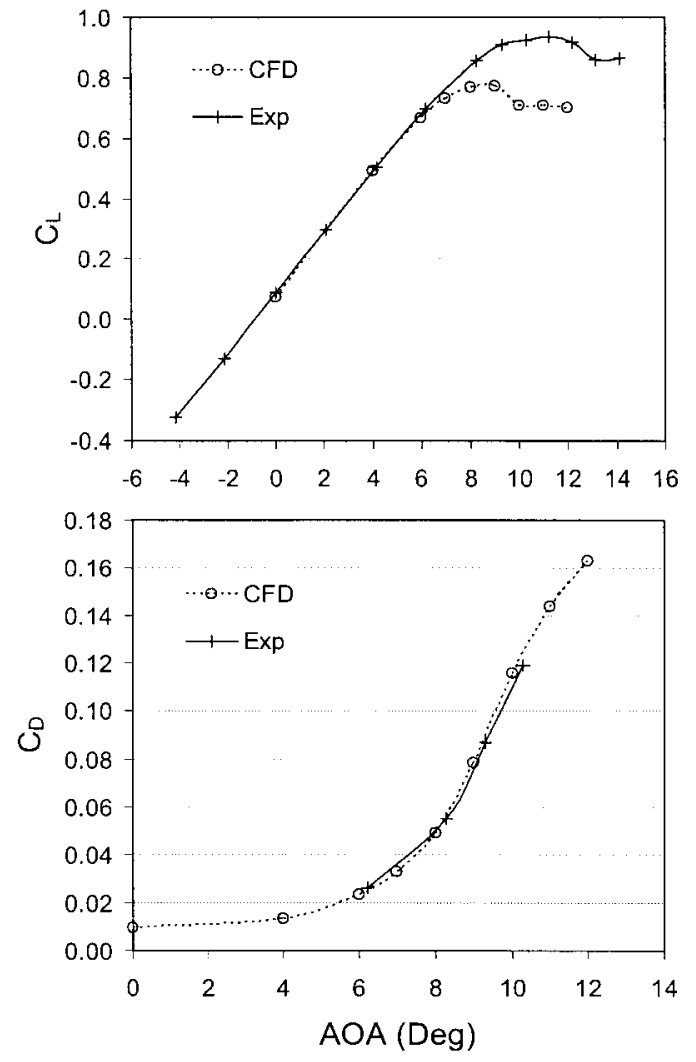

Fig. 16. Computed and measured lift and drag coefficients for GLC305 airfoil with 212 ice (M $=0.12$, P $\left.=20.5 \mathrm{psi}, \operatorname{Re}=3.5 \times 10^{6}\right)$. CFD: WIND, S-A model.

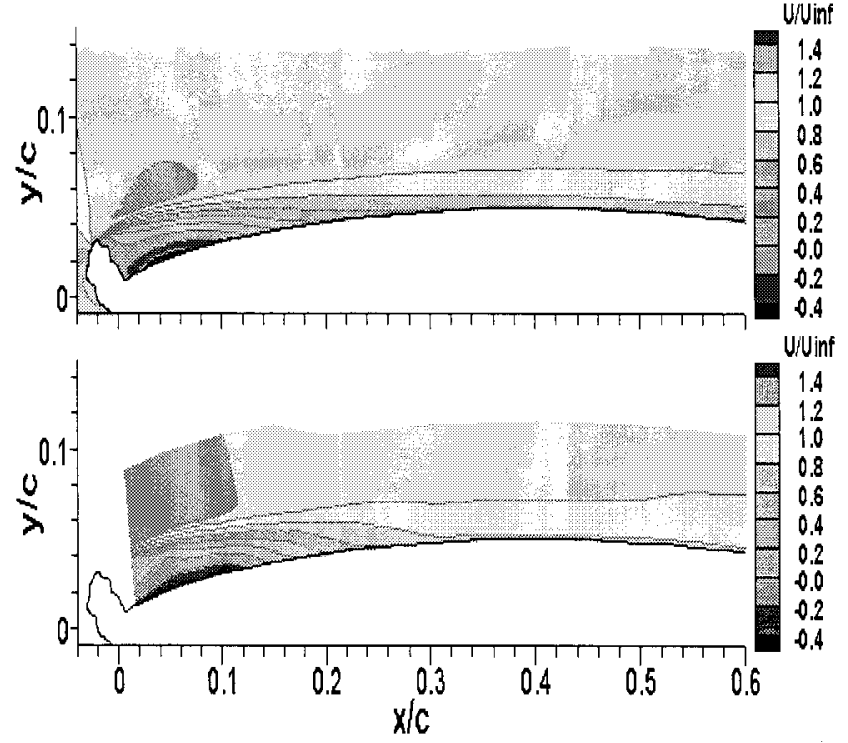

Fig. 18. Normalized $\mathrm{x}$-component velocity magnitude for GLC305 airfoil with 944 ice at $A O A=0^{\circ}(\mathrm{M}=0.12, \mathrm{P}=$ $20.5 \mathrm{psi}, \operatorname{Re}=3.5 \times 10^{6}$ ). Top: $\mathrm{CFD}$ with WIND and S-A model. Bottom: measurement (Ref. 12).
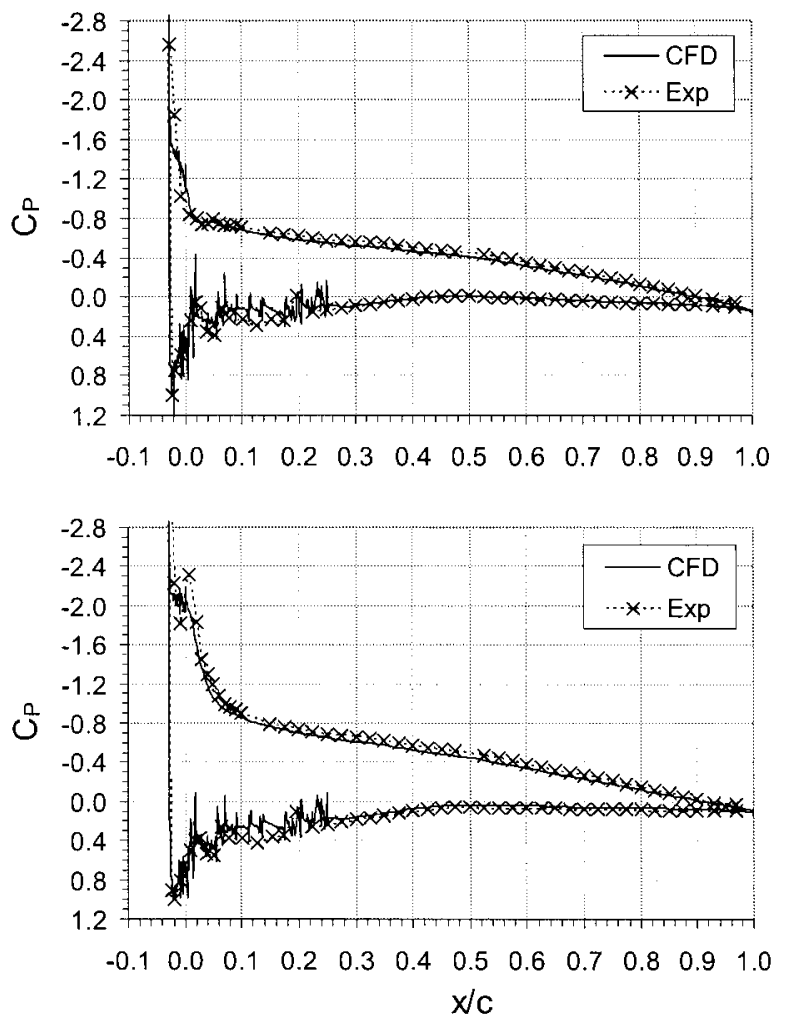

Fig. 17. Computed and measured pressure coefficient for GLC305 airfoil with 212 ice as a function normalized distance along the chord $\left(\mathrm{M}=0.12, \mathrm{P}=20.5 \mathrm{psi}, \mathrm{Re}=3.5 \times 10^{6}\right)$. Top: $\mathrm{AOA}=4^{\circ}$. Bottom: $\mathrm{AOA}=6^{\circ}$. CFD: Wind, S-A model.

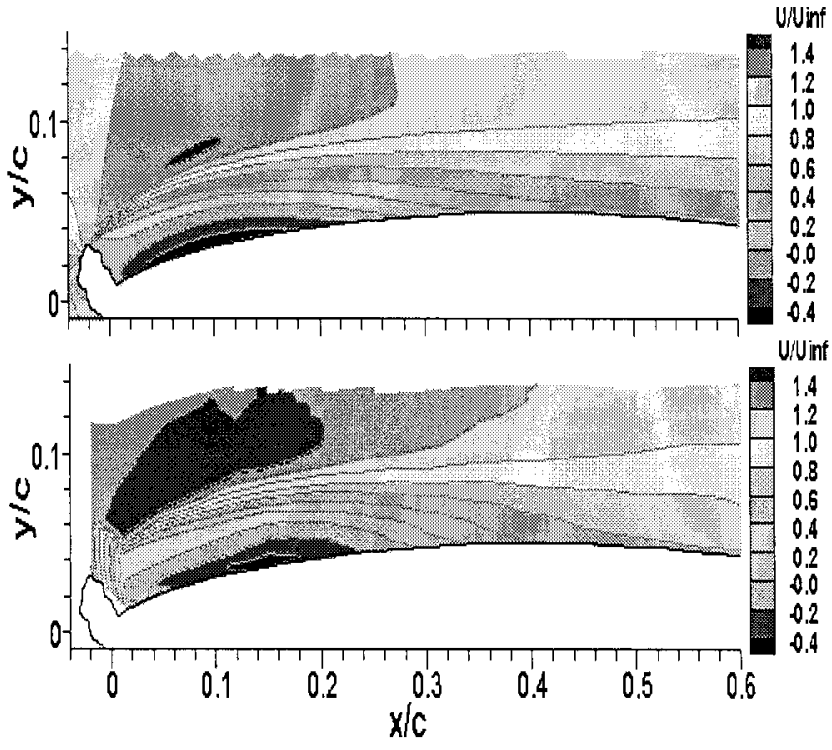

Fig. 19. Normalized $\mathrm{x}$-component velocity magnitude for GLC305 airfoil with 944 ice at $\mathrm{AOA}=4^{\circ}(\mathrm{M}=0.12, \mathrm{P}=$ $20.5 \mathrm{psi}, \mathrm{Re}=3.5 \times 10^{6}$ ). Top: CFD with WIND and S-A model. Bottom: measurement (Ref. 12). 

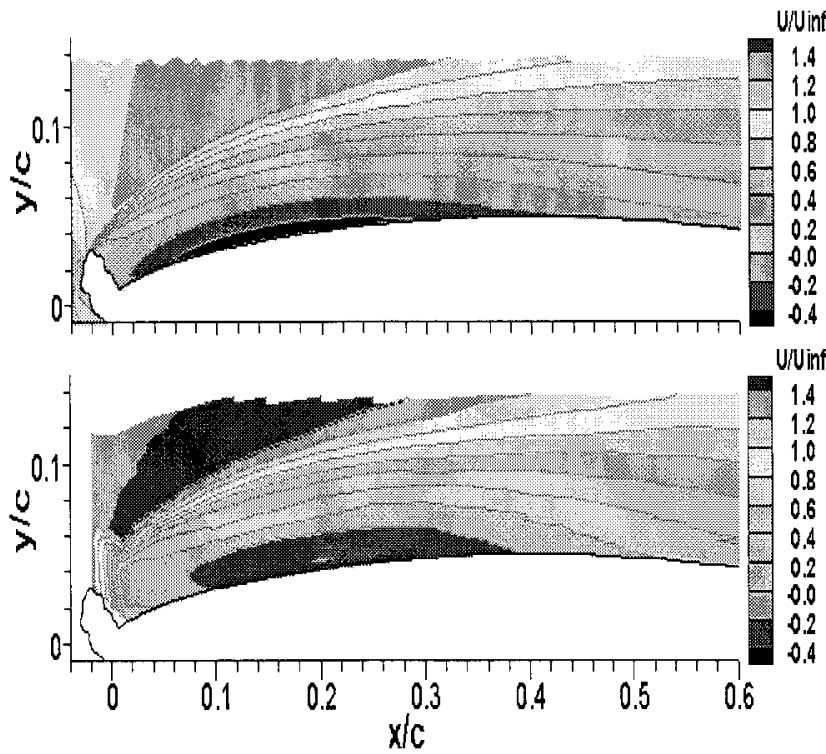

Fig. 20. Normalized $\mathrm{x}$-component velocity magnitude for GLC305 airfoil with 944 ice at $\mathrm{AOA}=6^{\circ}(\mathrm{M}=0.12, \mathrm{P}=$ 20.5 psi, $\operatorname{Re}=3.5 \times 10^{6}$ ). Top: CFD with WIND and $\mathrm{S}-\mathrm{A}$ model. Bottom: measurement (Ref. 12).

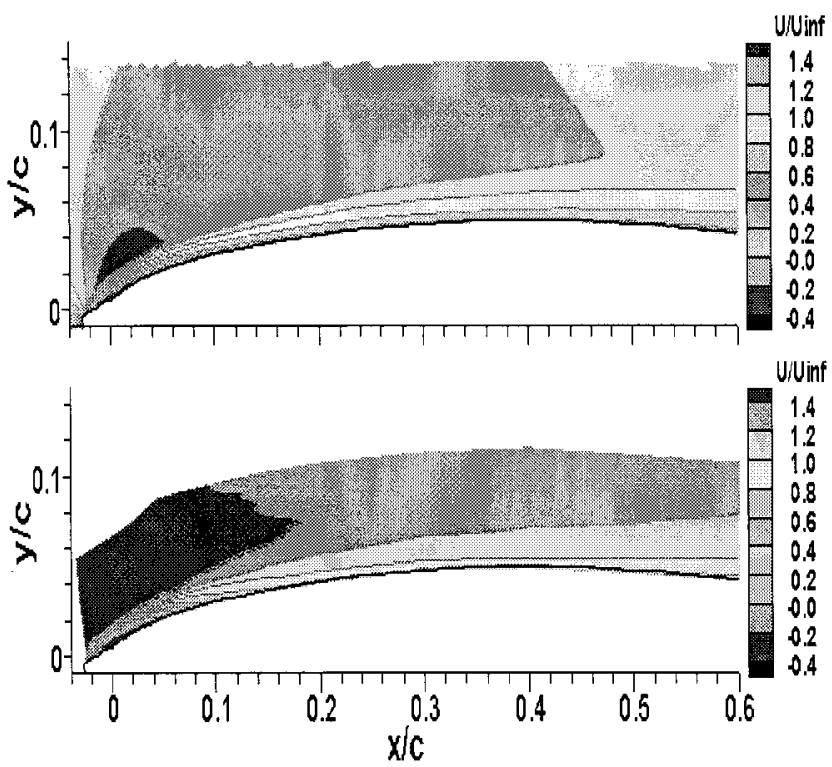

Fig. 21. Normalized $\mathrm{x}$-component velocity magnitude for GLC305 airfoil with 212 ice at $\mathrm{AOA}=6^{\circ}(\mathrm{M}=0.12, \mathrm{P}=$ $20.5 \mathrm{psi}, \operatorname{Re}=3.5 \times 10^{6}$ ). Top: CFD with WIND and S-A model. Bottom: measurement (Ref. 12).
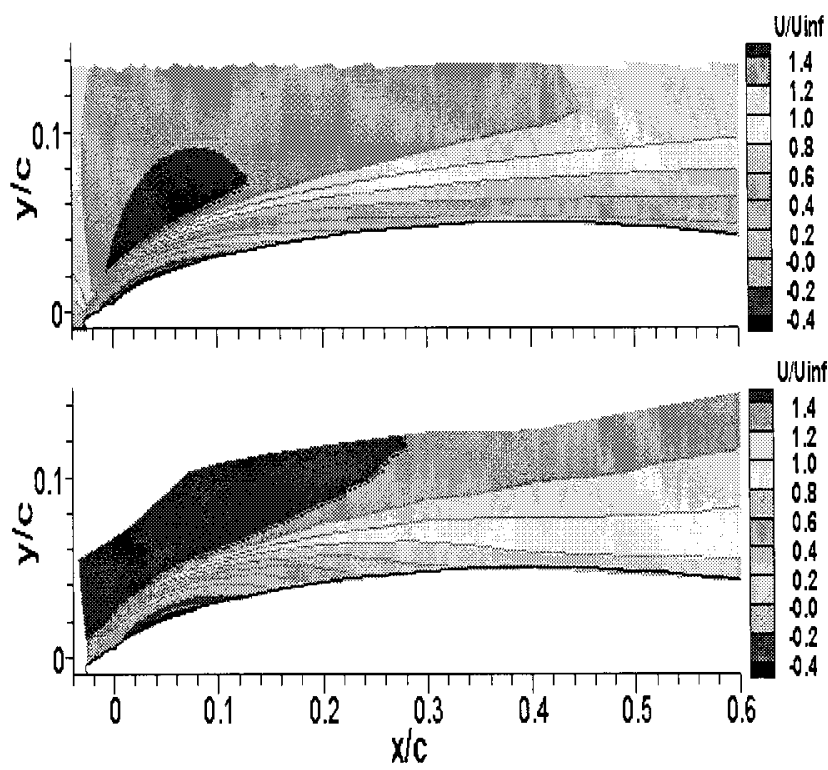

Fig. 22. Normalized $\mathrm{x}$-component velocity magnitude for GLC305 airfoil with 212 ice at $\mathrm{AOA}=8^{\circ}(\mathrm{M}=0.12, \mathrm{P}=20.5$ psi, $\operatorname{Re}=3.5 \times 10^{6}$ ). Top: CFD with WIND and S-A model. Bottom: measurement (Ref. 12). 